$<$ Original Research Paper $>$

\title{
Development of Continuous Flow Type Hydrothermal Reactor for Hemicellulose Fraction Recovery from Corncob
}

\author{
Satoshi Makishima $^{1,2}$, Masahiro Mizuno ${ }^{1}$, Nobuaki Sato ${ }^{1}$, Kazunori Shinji ${ }^{1,2}$, \\ Masayuki Suzuki ${ }^{2}$, Kouichi Nozaki ${ }^{1}$, Fumihiro Takahashi ${ }^{1}$, Takahisa Kanda ${ }^{1}$, \\ Yoshihiko Amano ${ }^{1 *}$ \\ ${ }^{1}$ Department of Chemistry and Material Engineering, Faculty of Engineering, \\ Shinshu University, 4-17-1 Wakasato, Nagano 380-8553, Japan \\ ${ }^{2}$ Research and Development Center, B Food Science Co. Ltd., \\ 24-12, Kitahamamachi, Chita, 478-0046, Japan
}

*Corresponding author;

E-mail: yoamano@shinshu-u.ac.jp

Tel \& Fax: +81-26-269-5394 


\begin{abstract}
The semi-pilot scale of continuous flow type hydrothermal reactor has been investigated to separate hemicellulose fraction from corncob. We obtained the effective recovery of hemicellulose using tubular type reactor at $200{ }^{\circ} \mathrm{C}$ for $10 \mathrm{~min}$. From constituent sugar analysis of corncob, $82.2 \%$ of xylan fraction was recovered as mixture of xylose, xylooligosaccharides and higher-xylooligosaccharide which has more than DP 10. During purification of solubilized fraction by hydrothermal reaction such as ultrafiltration and ion exchange resin, higher-xylooligosaccharide was recovered as the precipitate. This precipitate was identified as non-blanched xylan fraction which has from DP 11 to DP 21 mainly. In this system, only a small amount of furfural has been generated. This tubular reactor has a characteristic controllability of thermal history, and seems to be effective for sugar recovery from soft biomass like corncob.
\end{abstract}

Keywords: Hydrothermal reaction; Corncob; Xylooligosaccharide; Hemicellulose; Continuous flow reactor

Abbreviations: MALDI-TOFMS; Matrix-assisted laser desorption/ionization time-offlight mass spectrometry, 2,5-DHB; 2,5-dihydroxy benzoic acid, HPLC; high performance liquid chromatography 


\section{Introduction}

Biomass resources are becoming important as renewable and carbon-neutral materials for sustainable society, more than ever. They are not expected for only the food and energy sources, but also chemical materials through biomass refinery. Many researchers investigated remarkable biomass component recovery system such as bioprocesses, chemical processes (Mussatto et al., 2004), physicochemical processes and these combination processes (Wyman et al., 2005; Thomsen et al., 2008).

Above all the components of biomass, it has been reported that xylooligosaccharides isolated from hemicellulose fraction from various biomass are effective for intestinal disorders (Okazaki et al., 1990; Okazaki et al., 1991; Vázquez et al., 2000), and it will be expected as profitable products in the market of functional foods. From the point of view of hemicellulose recovery, we should select the origin of biomass resources. It is well known that the soft biomass such as corncob and cornstover contains a large amount of hemicellulosic component. Therefore various processes for recovering of hemicellulose fraction from these origins have been investigated.

We focused a development scheme on the hydrothermal reaction to produce a series of xylooligosaccharides, because it has been reported as effective fractionation method for three major components of lignocellulosic biomass (i.e. hemicellulose, cellulose and lignin) (Saka et al., 2005; Parajó et al., 2004; Garrote et al., 1999; Sasaki et al., 2003; Goto et al., 2004). The moderate hydrothermal reaction process without chemicals such as acid or alkali is thought to be desirable for environmental reasons, because it is not necessary to neutralize and desalt with liquid-waste treatment. In addition, it is remarkable point that the hydrothermal reaction process for xylooligosaccharides production from corncob has been analyzed based on kinetic modeling (Garrote et al., 2001; 2002; Parajó et al., 2004; Vázquez et al., 2006).

In a previous paper, the waste medium for Enokitake (Flammulina velutipes) mushroom cultivation mainly consisting of corncob was tested for hydrothermal reaction to recover soluble sugars (Makishima et al., 2006). The soluble fraction obtained from corncob in the waste medium by hydrothermal reaction under $190^{\circ} \mathrm{C}$ contained large amounts of xylose and xylooligosaccharides. However, the waste medium contains rich nutrient (e.g. protein and amino acid) which acts as impurities. If suitable biomass resource is used and the hydrothermal reaction conditions are strictly controlled, it will be able to prevent the buildup of furfural and colored impurity components that interrupt purification processes.

In this paper, the continuous flow type hydrothermal reactor was constructed as semi-pilot plant scale, and effective recovery of hemicellulose fraction from pure corncob has been investigated with the developed reactor.

\section{Materials}




\subsection{Corncob}

Dried corncob made in the north area of China was obtained. The dried corncob was ground and selected out heavy weight fraction by air blow process. Most of the heavy weight fraction called "grid" part which is middle layer of corncob. The part corncob was additionally pulverized and classified according to the mesh size of 120 150 mesh (the opening size is about $100-125 \mu \mathrm{m}$ ). This pulverized corncob was mixed with water to prepare slurry form for the hydrothermal reaction test in this study.

\subsection{Compositional analysis for corncob}

Corncob composition was determined by following method. The ethanol-benzene extract was determined by Soxhlet extraction method. Klason-Lignin content was determined using $72 \%$ sulfuric acid by the method of JIS P8008; 1976. Acid soluble lignin was determined by the absorbance $(\lambda=210 \mathrm{~nm})$ of acid digestion solution for the Klason-lignin method (absorption constant of lignin as $113[\mathrm{~L} / \mathrm{g} \cdot \mathrm{cm}]$ ). Ash content was determined from the residual weight after incinerate at $600{ }^{\circ} \mathrm{C}$. Cellulose (glucan), xylan, arabinan contents were determined using quantitative acid hydrolysis method described by Kaar, et al. (1991).

\subsection{Continuous flow type hydrothermal reactor}

Semi-pilot scale continuous flow type hydrothermal reactor system was developed, and it was used for hemicellulose recovery test for corncob. Fig. 1 illustrates the structure of developed reactor system consisted of material feeder, tube shape hydrothermal reactor and product discharge units. General design specification of reactor system is summarized in Table 1. All tube reactors were designed that temperature is $230^{\circ} \mathrm{C}$ and pressure is $3.0 \mathrm{MPa}$. Throughput of the reactor system is 3 $\mathrm{kg} / \mathrm{h}$ as dried corncob $(20 \mathrm{~kg} / \mathrm{h}$ as slurry form raw material). Total system size is $\mathrm{W}$ $3000 \mathrm{~mm} \times$ D $2050 \mathrm{~mm} \times \mathrm{H} 2500 \mathrm{~mm}$ within the compact size of 10 tons truck transportation for the purpose of mobile hydrothermal reactor and achievement of onsite biomass treatment. The reactor system was manufactured by Kimura Chemical Plants Co. Ltd. (Amagasaki, Hyogo, Japan).

The material feeder unit adapted mohno slurry pump (the NEMO ${ }^{\circledR}$ pump, 13 stages type, Heishin-sobi Co. Ltd.) integrated with a material distribution tank for feeding slurry form material smoothly into the tube shape reactor. To grind solid biomass material mixing with water, the wet grinder (MKCA 6-3, Masuko Sangyo Co., Ltd.) was also mounted in this system. In addition to the slurry pump, solvent feeding pump was arranged in the feeder unit. The solvent feeding system is able to control liquid condition and retention time of material in the hydrothermal reactor tube.

The hydrothermal reactor was made with SUS316 tube (outer diameter of 25.4 $\mathrm{mm}$, thickness of $2.1 \mathrm{~mm}$ ). The hydrothermal reactor is sectionalized into heat-up divisions $(\mathrm{H} 1, \mathrm{H} 2)$, reaction divisions ( $\mathrm{R} 1$ to $\mathrm{R} 4)$ and cool-down divisions $(\mathrm{C} 1, \mathrm{C} 2)$, and 
tube length of each divisions are $4.5 \mathrm{~m}, 10.4 \mathrm{~m}$ and $4.5 \mathrm{~m}$, respectively. Preheating tube and reactor tube were heated up by electrical heaters and cooling tube was chilled by water. Temperature of each section was monitored with a number of thermocouples. All reactor tube is on a slight slope to keep material flowing.

The product discharge unit consists of double cylinder valves and pressure hold vessel which is located on the center of double cylinder valve. The pressure inside of reactor tube was adjusted by alternately working double cylinder valves in conjunction with the pressure sensor. Although a momentary pressure drop occurred when the open and shut the up-stream cylinder valve, compressed air in the pressure hold vessel absorbs pressure fluctuation shock. Then, immediately open the down-stream cylinder valve, and reacted products were extruded by compressed air. The compressed air in the pressure hold vessel supports smooth delivery of slurry reaction product. Working sequence of cylinder valves was automated with pressure-controlled actuators.

\subsection{Continuous hydrothermal reaction test}

In the continuous hydrothermal reaction test for corncob, the flow type reactor system was warmed up to preset reaction conditions with feeding water by the cylinder pump. Then, the slurry raw material was fed by the mohno pump to start the experimental run. After stabilize conditions of the reactor system, hydrothermal reacted slurry products were collected, and its elution flow rate was measured by electric scales. The reaction products were fractionated to the soluble fraction and the residual fraction by centrifuging and filtrating. The residual fraction was washed with hot water to remove soluble products, and then measured dried weight. The weight of water soluble fraction was calculated from the mass balance of the collected reaction product and the residual fraction.

\subsection{HPLC analysis of sugars in the soluble fraction}

The amount of sugars and its composition contained in the water soluble fraction obtained after hydrothermal treatment from corncob were analyzed by high performance liquid chromatography (HPLC) equipment with refractive index detector. The sample was filtrated with $0.45 \mu \mathrm{m}$ membrane before HPLC analysis. Constituent sugars of xylooligosaccharide were analyzed by the HPLC conditions with Aminex HPX-87H column (7.8 mm I.D. $\times 300 \mathrm{~mm}$, BioRad). The column temperature was controlled at $65^{\circ} \mathrm{C}$, and mobile phase was $4 \mathrm{mM}$ of sulfuric acid solution, pumped at $0.6 \mathrm{~mL} / \mathrm{min}$. The concentration of xylooligosaccharide was evaluated using the $1.0 \mathrm{mg} / \mathrm{mL}$ external standard. To analyze the sugar composition of xylooligosaccharide, a portion of the water soluble fraction was subjected to quantitative hydrolysis treatment (boiled with $1 \mathrm{~N}-\mathrm{H}_{2} \mathrm{SO}_{4}$ for $2 \mathrm{~h}$, in the boiling water bath), and then diluted with distilled water to adjust concentration of sulfuric acid for above HPLC analysis. Further analysis of the polymerization degree of xylooligosaccharide was conducted with a MCIGEL CK02S 
column (20 mm I.D. $\times 250 \mathrm{~mm}$, Mitsubishi Chemical Co.) which temperature was controlled at $85^{\circ} \mathrm{C}$, and mobile phase was distilled water, pumped at $1.0 \mathrm{~mL} / \mathrm{min}$.

\subsection{MALDI-TOFMS analysis of xylose-oligomers and -polymer}

Water soluble fraction after hydrothermal treatment was deionized using Amberlite MB-3 resin (ORGANO Co.) to remove various salts and then applied to charcoal column chromatography to remove phenolic compounds. Then $1 \mu \mathrm{L}$ of mixture of xylooligosaccharides ( $0.6 \%$, Brix degree) and $10 \mu \mathrm{L}$ of matrix solution (10 $\mathrm{mg}$ of 2,5DHB in $1 \mathrm{~mL}$ of distilled water) were shaken vigorously on a vortex mixer. One $\mu \mathrm{L}$ of solution was loaded onto the sample plate. The sample plate was allowed to dry and crystallize for about $10 \mathrm{~min}$ at room temperature and was subsequently loaded into Axima CFRplus (Shimadzu Biotech, $120 \mathrm{~cm}$ ion path length in liner mode). A nitrogen laser $(337 \mathrm{~nm})$ was used for the ionization (Sumi et al., 2000).

\subsection{Purification process of xylooligosaccharide solution}

To get food grade xylooligosaccharide, several purification procedures were applied for hydrothermal water soluble fraction. First step was UF membrane (NTU3050-CIR, Nitto Denko Corp.) filtration for decolorization, and second step was NF membrane (NTR-7450, Nitto Denko Corp.) for elimination of monosaccharide and concentration. Third step was activated carbon treatment with controlling $\mathrm{pH}$ less than 4.0 for second decolorization. And then, ion exchange demineralization and final activated carbon treatment was applied. Finally, purified xylooligosaccharide solution was concentrated by vacuum evaporation. (Kazunori Shinji, JP 2008-56599A)

\section{Results and discussion}

\subsection{Preparation of corncob for the developed flow type reactor system.}

To confirm the suitable particle size distribution of corncob for the developed flow type reactor system, several kinds of corncob sample were tested with preparing slurry form of them. The corncob which was pulverized and classified to the size 120-150 mesh grade was most suitable in the tested four kinds of corncob powder. Mean diameter of the corncob was $118 \mu \mathrm{m}$, and accumulated frequency of the corncob size was $35 \mu \mathrm{m}(10 \%), 109 \mu \mathrm{m}(50 \%), 207 \mu \mathrm{m}(90 \%)$. Corncob slurry was prepared by dispersing solid particle of the corncob into water uniformly. Viscosity of the slurry was $1.8 \mathrm{dPa} \cdot \mathrm{s}$ (at $23{ }^{\circ} \mathrm{C}$ ) in the concentration of $13.5 \mathrm{wt} \%$. Based on the preliminary test preparing slurry form of corncob, the slurry corncob in the concentration of up to $15 \mathrm{wt} \%$ was able to keep high fluidity. But fluidity of slurry corncob in the concentration of over $17 \mathrm{wt} \%$ tended to deteriorate, and its viscosity was $38 \mathrm{dPa} \cdot \mathrm{s}$ (at $23{ }^{\circ} \mathrm{C}$ ). Upperlimit of acceptable concentration of corncob slurry might be in the range from $15 \mathrm{wt} \%$ to $17 \mathrm{wt} \%$ for the developed reactor system. 
The composition of corncob used in this study was as follows; cellulose (as glucan), 29.7\%; xylan, 29.9\%; arabinan, 3.4\%; Klason-lignin, 12.7\%; acid-soluble lignin, 2.6\%; ethanol-benzene extractives, 2.7\%; ash, 3.5\%; others (by difference), 15.5\%, on the basis for dried corncob weight.

\subsection{Controllability of the flow type hydrothermal reactor system}

Fig. 2a shows typical temperature profiles during experimental run. After warmed up the hydrothermal reactor system, the slurry raw material was fed by the mohno pump to start the experimental run. Operation time was set as $0 \mathrm{~min}$ at this point. Fed slurry material was passed through heat-up divisions ( $\mathrm{H} 1, \mathrm{H} 2)$, reaction divisions (R1 to $\mathrm{R} 4$ ), cool-down divisions $(\mathrm{C} 1, \mathrm{C} 2)$ and discharge division in order, and reaction product was discharged $25 \mathrm{~min}$ later. Although wide fluctuations of temperature at each division were observed within $15 \mathrm{~min}$, it was stabilized over $25 \mathrm{~min}$. The temperature of each reaction tube ( $\mathrm{R} 1$ to $\mathrm{R} 4$ ) was controlled to $190 \pm 5^{\circ} \mathrm{C}$ (in this case, $190^{\circ} \mathrm{C}$ setting) after stabilized.

Fig. $2 \mathrm{~b}$ shows the controllability of pressure in the hydrothermal reactor system during the experimental run. In this system, pressure was controlled by working sequence of double cylinder valves at the product discharge unit. Although, a small pressure drop was observed when work cylinder valves, it can keep pressure with periodic variation in range of 1.5 to $1.8 \mathrm{MPa}$. Pressure profile became steady because the reactor tube filled up with slurry material over 15 min after start experimental run. Subsequently, stable continuous operation was achieved over 6 hours on hydrothermal treatment of corncob slurry in the high concentration of $13.5 \mathrm{wt} \%$ or less.

Our developed reactor system is a typical tubular reactor which it is able to flow the solid biomass material with the solvent water. One of the major advantages of this type of reactor system is expected to be high ratio of solid material to water by comparison with the solvent flow type system. Since the ratio of water to corncob was equivalent to $6.4 \mathrm{~kg} / \mathrm{kg}$ of dried corncob in this work, it achieves effective recovery of soluble sugar products in high concentrations, as discussed in following section. Meanwhile there is the disadvantage that is hard to raise concentration of raw material than a certain level in order to keep fluidity of the slurry raw material in the tubular reactor system. Moreover scale-up of the developed flow type reactor system remains some technical issues such as influences temperature and concentration gradients inside tubular reactor. We should design the industrial scale hydrothermal reactor based on the continuous flow system by solving those technical issues.

\subsection{Hemicellulose fraction recovery from corncob with the continuous flow type hydrothermal reactor}

Table 2 shows the operation conditions performed continuous hydrothermal reaction test for corncob. From the actual average temperature of each divisions of 
reaction tube (R1-R4) during a sampling period, it was classified in the temperature of $200^{\circ} \mathrm{C}, 205^{\circ} \mathrm{C}$ and $210^{\circ} \mathrm{C}$. Time in the Table 2 was residence time in whole reaction division (R1 to R4), and it was estimated from the mass flow rate of reacted slurry by correcting the fluid density data at the elevated temperature and pressure. The density data of water was used instead of the fluid density data of corncob slurry at the elevated conditions, in this study. The concentration of corncob in the slurry raw material was $13.5 \mathrm{wt} \%$. Actual concentration of corncob was determined from the weight of dried substance in the reaction products which contained both of the soluble fraction and the residual fraction, and it was almost equal to the set concentration. Brix degree for the soluble fractions was about $7 \%$ highly, at every conducted reaction conditions. On the reaction temperature of $200^{\circ} \mathrm{C}, 32.8$ to $34.9 \mathrm{wt} \%$ of corncob was solubilized by the hydrothermal reaction, the solubilization ratio increased with reaction time. The contents of xylan and arabinan which is constituent hemicellulose of corncob used in this study were $29.9 \mathrm{wt} \%$ and $3.4 \mathrm{wt} \%$ respectively. Since the solubilization and decomposition of cellulose are hard to occur in the temperature of around $200^{\circ} \mathrm{C}$, it was suggested that most part of soluble fraction was derived from the hemicellulose fraction of corncob.

Table 3 shows the concentration of sugar products in the soluble fraction recovered from corncob. The soluble fraction included xylose-oligomers mainly, and xylose, arabinose and glucose were also included. In addition, furfural as decomposition product of pentose such as xylose and arabinose were presented in the soluble fraction. The concentration of total xylose-oligomers (as XO) was 3.2 to $3.7 \mathrm{wt} \%$ and xylose was 0.7 to $1.0 \mathrm{wt} \%$. It was comparable to the previous reported data obtained by using batch type reactor with the corncob concentration of $11.1 \mathrm{wt} \%$ (Vazquez, et al. 2006). As our developed reactor system is able to continuously feed solid corncob with solvent water by preparing the slurry form raw material, high concentration of xylooligosaccharides and xylose were recovered in the soluble fraction after the hydrothermal reaction, as compare with the solvent flow type hydrothermal reactor (Mok et al., 1992, Sasaki et al., 2003; Liu and Wyman, 2005).

Based on the polymerization degree (DP) analysis, xylose-oligomers in the soluble fraction were classified to the xylooligosaracharide (from DP2 to DP10, as $\mathrm{XO}_{\mathrm{L}}$ ) and the higher-xylooligosaracharide (more than DP 11, as $\mathrm{XO}_{\mathrm{H}}$ ). The ratio of the higherxylooligosaracharide decreased with reaction time. At the longer reaction time, the concentration of $\mathrm{XO}$ (summation of $\mathrm{XO}_{\mathrm{L}}$ and $\mathrm{XO}_{\mathrm{H}}$ ) decreased, and the concentration of monomer sugars such as xylose increased. Such reaction behavior agreed in the reaction path model of xylan component under the hydrothermal conditions that is reported by Garrote, et al. (Garrote, et al., 2002).

Table 4 shows the yield of reaction products obtained at a part of operating conditions which has recovered enough amount of reaction product for the mass balance calculation. A total of the yields for the soluble fraction and the residual fraction 
reached almost $100 \%$, and the accuracy of the analytical procedure conducted in this study was confirmed. Adequate operating conditions that provided highest yield of soluble sugars was the temperature of $200{ }^{\circ} \mathrm{C}$ and reaction time of $10.7 \mathrm{~min}$, on Table 4 , and $24.4 \mathrm{wt} \%$ of dried corncob and $6.6 \mathrm{wt} \%$ of it were recovered as xylose-oligomers and xylose respectively. On the contrary, the yield of furfural which was undesirable byproduct was controlled to less than $2 \mathrm{wt} \%$. Table 5 shows theoretical yields of xylan related products as basis for the weight of xylan in the corncob. Under the maximal reaction conditions at $200{ }^{\circ} \mathrm{C}$ for $10.7 \mathrm{~min}, 62.2 \%$ of xylan fraction and $20.0 \%$ of it were recovered as xylose-oligomers and xylose, respectively, and the total yield was $82.2 \%$. Production of furfural was controlled to $6.6 \%$. These data suggests that the reaction conditions were controlled in the consecutive reaction path which consists of xylan, xylose-oligomer, xylose, furfural and others in series. To develop industrial scale hydrothermal reactor, we should continue further investigation based on the kinetic approach (Garrote, et al., 2001; 2002; Parajó et al., 2004).

\subsection{Analysis of purified xylooligosaccharide solution}

Since high concentration of xylose and xylooligosaccharide was recovered in the soluble fraction from corncob, the purification test was conducted to get food grade xylooligosaccharide. DP of xylooligosaccharides contained in the purified solution was analyzed by HPLC, as shown in Fig. 3. After the purification process, the purified xylooligosaccharide solution (Purified XO solution, fresh) contained a series of xylooligosaccharides up to xylodecaose (DP10), and those more than DP10 were also existed as shown in Fig. 3b. We can see the purified XO solution contained higher concentration of xylooligosaccharides than the soluble fraction after the hydrothermal reaction (Crude XO solution, as shown in Fig. 3a). In addition, a large peak of highmolecular fraction in the crude XO solution observed on Fig. 3a, but the peak was disappeared in the purified XO solution (Fig. 3b). It is indicated that high-molecular impurities such as soluble lignin were removed by purification procedure like the membrane and activated carbon treatment.

When purified XO solution was preserved for over one month, some white precipitates were observed in the purified XO solution. So the supernatant and the precipitate were analyzed by HPLC. A little amount of the precipitate was able to dissolve in water at room temperature. The residual insoluble precipitate was forced to dissolve in boiling water, and then sample solution was obtained. In the supernatant (Fig.3c), peak of high-molecular fraction over DP9 was decreased compare with the fresh purified XO solution (Fig.3b). On the other hand, high-molecular fraction was increased in the water soluble precipitate (Fig. 3d), and high-molecular fraction over DP12 was detected in the boiling water soluble precipitate (Fig. 3e).

Further the large size of xylooligosaccharides contained in the precipitate (after fully dissolved by boiling with dilute $\mathrm{NaOH}$ solution) was analyzed by MALDI- 
TOFMS. The precipitate contained xylooligosaccharides from DP10 to DP21. The observed peaks were completely coincident with the molecular size of xylooligosaccharides complexed with sodium ion. The differences of molecular size of adjacent two peaks were almost $132 \mathrm{Da}$, which same as molecular size of dehydrated xylose unit.

It is suggested that the white precipitate consisted of almost xylose unit from the analysis data by the acid hydrolysis method, and it was identified as homooligosaccharides. Incidentally, sugar composition of the purified XO solution was xylose: glucose: arabinose $=90.3: 3.7: 6.0$, in the weight ratio, and it was able to define as hetero-oligosaccharides.

As the result of hydrothermal reaction of corncob, the xylooligosaccharides up to DP10 are relatively stable in solution, the high-molecular oligosaccharides more than DP10 have lower solubility in water. In addition, the solubility of heterooligosaccharides consisting of arabinose and glucose as side chain of xylan were higher than homo-oligosaccharide consist of nonbranching-xylooligosaccharides.

\section{Conclusion}

Hydrothermal reaction was effective method to degrade hemicellulosic biomass to xylose and xylooligosaccharides into the soluble fraction. In this time, we succeeded in constructing a continuous flow type hydrothermal reactor with the pilot scale. Preparation of the adequate material slurry allowed for continuous running over 6 hours. From the assessment based on the production of xylose and xylooligosaccharide, the production ability of these saccharides by this flow type reactor is almost equal the one by batch type reactor. Dried corncob contains about $29.9 \%$ of hemicellulose as xylan, and $29.7 \%$ of cellulose. By evaluating the hydrothermal processes, $1 \mathrm{~kg}$ of xylose and xylooligosaccharides was recovered from $4 \mathrm{~kg}$ of corncob including $1.2 \mathrm{~kg}$ xylan, and theoretical yield was over $82 \%$. A series of xylooligosaccharides obtained from xylan, which were unique homo- and hetero-oligosaccharides with up to DP20 were detected in the soluble fraction. In this way, the development of pilot scale flow type hydrothermal reactor expanded the possibility of full commercial scale production for a series of xylooligosaccharides.

In recent years, xylooligosaccharides have been well known on the food material market, but the commercial product contains mainly from xylobiose (DP2) to xylotetraose (DP4), as they were produced by fermentation or enzymatic method. On the other hand, xylooligosaccharides produced by hydrothermal reaction has wide range of degree of polymerization, and they are interesting material for food application.

\section{Acknowledgements}


This research was supported by Research and Development Program for New Bioindustry Initiatives (2004 - 2008) of Bio-oriented Technology Research Advancement Institution (BRAIN), Japan. 


\section{References}

Garrote, G., Domínguez, H. and Parajó, J.C., 1999. Mild autohydrolysis: an environmentally friendly technology for xylooligosaccharide production from wood. J. Chem.Tecnol. Biotechnol., 74, 1101-1109.

Garrote, G., Domínguez, H. and Parajó, J.C., 2001. Kinetic modeling of corncob autohydrolysys. Process Biochem., 36, 571-578.

Garrote, G., Domínguez, H. and Parajó, J.C., 2002. Autohydrolysis of corncob: study of non-isothermal operation for xylooligosaccharides production. Journal of Food Engineering, 52, 211-218.

Goto, M., Obuchi, R., Hirose, T., Sakaki, T., Shibata, M., 2004. Hydrothermal conversion of municipal organic waste into resources. Bioresour. Technol., 93, 279-284.

Liu, C. and Wyman, C.E., 2005. Partial flow of compressed-hot water through corn stover to enhance hemicellulose sugar recovery and enzymatic digestibility of cellulose. Bioresour. Technol., 96, 1978-1985.

Kaar, W. E., Cool, L. G., Merriam, M. M., 1991. The complete analysis of wood polysaccharides using HPLC. J. Wood Chem. Technol., 11(4), 447-463.

Makishima, S., Nozaki, K., Mizuno, M., Netsu, E., Shinji, K., Shibayama, T., Kanda, T. and Amano, Y., 2006. Recovery of soluble sugars from waste medium for Enokitake (Flammulina velutipes) mushroom cultivation with hydrothermal reaction and enzyme digestion. J. Appl. Glycosci., 53, 261-266.

Mok, W. S., Antal, M. J., 1992. Unanalyzed Solvolysis of Whole Biomass Hemicellulose by Hot Compressed Liquid water. Ind. Eng. Chem. Res., 31, 11571161.

Mussatto, S.I. and Roberto, I.C., 2004. Alternatives for detoxification of diluted-acid lignocellulosic hydrolyzates for use in fermentative processes: a review. Bioresour. Technol., 93, 1-10.

Okazaki, M., Fujikawa, S. and Matsumoto, N., 1990. Effect of xylooligosaccharide on the growth of Bifidobacteria. Bifidobacteria Microflora, 9, 77-86

Okazaki, M., Koda, H., Izumi, R. and Matsumoto, N., 1991. Effect of xylooligosaccharide on growth of intestinal bacteria and putrefaction product. Japanese Society Nutrition and Food Science, 44, 41-44.

Parajó, J.C., Garrote, G., Cruz, J.M. and Domínguez, H., 2004. Production of xylooligosaccharides by autohydrolysis of lignocellulosic materials. Trends in Food Science \& Technology, 15, 115-120.

Saka, S., Ehara K. and Minami, E., 2005. Efficient Utilization of Woody Biomass with Supercritical Fluid Technologies. Mokuzai Gakkaishi (written in Japanese), 51, 207-217. 
Sasaki, M., Adschiri, T., Arai, K., 2003. Fractionation of sugarcane bagasse by hydrothermal treatment. Bioresource Technol., 86, 301-304.

Shinji, K., 2008. Production method of xylose-polymer and its hydrogenerated reduction product, Japanese patent, JP 2008-56599A.

Sumi, T., Sakaki, T., Ohba, H., Shibata, M., 2000. Application of matrix-assisted laser desorption/ionization time-of-flight mass spectrometry to insoluble glucose oligomers in decomposed cellulose. Rapid Commun. Mass Spectrom., 14, 18231827.

Thomsen, M.H., Thygesen, A., Thomsen, A.B., 2008. Hydrothermal treatment of wheat straw at pilot plant scale using a three-step reactor system aiming at high hemicellulose recovery, high cellulose digestibility and low lignin hydrolysis. Bioresource Technology, 99, 4221-4228.

Vázquez, M.J., Alonso, J.L., Domínguez, H. and Parajó, J.C., 2000.

Xylooligosaccharides: manufacture and applications. Trends in Food Science \& Technology, 11, 387-393.

Vázquez, M.J., Garrote, G., Alonso, J.L., Domínguez, H. and Parajó, J.C., 2006. Enhancing the potential of oligosaccharides from corncob autohydrolysis as prebiotic food ingredients. Industrial Crops and Products, 24, 152-159.

Wyman, C.E., Dale, B.E., Elander, R.T., Holtzapple, M., Ladisch, M. R. and Lee, Y.Y., 2005. Comparative sugar recovery data from laboratory scale application of leading pretreatment technologies to corn stover. Bioresour. Technol., 96, 2026-2032. 


\section{Figure Captions}

Fig. 1 Schematic diagram of continuous flow type hydrothermal reactor system.

Fig. 2. Controllability of the flow type hydrothermal reactor system.

(a) Temperature distribution in the hydrothermal reactor; Raw material (gray bold line); Heat-up division, $\mathrm{H} 1$ and $\mathrm{H} 2$ (dashed thin lines); Reaction division, R1 to R4 (four thick lines), Cool-down division, C1 and C2 (two thin lines), (b) Pressure fluctuation in the hydrothermal reactor.

Fig. 3. Degree of polymerization (DP) of xylooligosaccharide solution obtained by the purification process.

(a) Crude XO solution. (b) Purified XO solution, fresh. (c) Supernatant, preserved the purified XO solution. (d) Precipitate resolved by water, preserved the purified XO solution. (e) Precipitate resolved by boiling water, preserved the purified XO solution. 
1 Table 1. Specification of designed continuous flow type hydrothermal reactor.

\begin{tabular}{|c|c|c|}
\hline Material feeder unit & & (Material) \\
\hline \multirow{2}{*}{ Slurry feed part } & $\begin{array}{l}\text { Snake type mohno pump } \\
\text { Discharge flow rate: Max. } 350 \mathrm{~mL} / \mathrm{min} \\
\text { Discharge pressure: Max } 3.0 \mathrm{MPa}\end{array}$ & $\begin{array}{l}\text { SUS316 (Stater) } \\
\text { Hard rubber (Cavity) }\end{array}$ \\
\hline & $\begin{array}{l}\text { Material distribution tank; Vol.: } 45 \mathrm{~L} \\
\text { (equipped with disk turbine type mixer) }\end{array}$ & SUS316 \\
\hline \multirow[t]{2}{*}{ Solvent feed part } & $\begin{array}{l}\text { Plunger pump } \\
\text { Discharge flow rate: Max. } 350 \mathrm{~mL} / \mathrm{min} \\
\text { Discharge pressure: Max. } 3.0 \mathrm{MPa}\end{array}$ & SUS316 / Tefron \\
\hline & Solvent tank; Vol: $25 \mathrm{~L}$ & SUS304 \\
\hline \multicolumn{3}{|l|}{ Hydrothermal reactor } \\
\hline \multirow[t]{2}{*}{ Heat-up division } & $\begin{array}{l}\text { Preheating tube; } \\
\text { Vol. 1.6 L, O.D.: } 25.4 \mathrm{~mm} \text {, I.D.: } 21.2 \mathrm{~mm} \text {, Length: } 4.5 \mathrm{~m} \\
\text { (sectionalized two divisions, H1 and H2) }\end{array}$ & \\
\hline & Metalock heater; $[200 \mathrm{~V} \times 1 \Phi \times 1.25 \mathrm{~kW}] \times 6 \mathrm{pcs}$ & \\
\hline \multirow[t]{2}{*}{ Reaction division } & $\begin{array}{l}\text { Reactor tube; } \\
\text { Vol.: } 3.6 \text { L, O.D.: } 25.4 \mathrm{~mm} \text {, I.D.: } 21.2 \mathrm{~mm} \text {, Length: } 10.4 \mathrm{~m} \\
\text { (sectionalized four divisions, R1 to R4) }\end{array}$ & SUS316 \\
\hline & Super sheathed heater; $[200 \mathrm{~V} \times 1 \Phi \times 1.0 \mathrm{~kW}] \times 4$ pcs & \\
\hline Cool-down division & $\begin{array}{l}\text { Cooling tube (Double wall water chilled type); } \\
\text { Vol.: 1.6 L, O.D.: } 25.4 \mathrm{~mm} \text {, I.D.: } 21.2 \mathrm{~mm} \text {, Length: } 4.5 \mathrm{~m} \\
\text { (sectionalized two divisions, C1 and C2) }\end{array}$ & SUS316 \\
\hline \multicolumn{3}{|l|}{ Product discharge unit } \\
\hline & $\begin{array}{l}\text { Pressure reduce system (Fixed displacement type); } \\
\text { [C/O cylinder valves, Pressure hold vessel, Air compressor, etc.] }\end{array}$ & SUS304 \\
\hline & Material recovery tank; Vol.: $25 \mathrm{~L}$ & SUS316 \\
\hline
\end{tabular}


1 Table 2. Operation conditions on the hydrothermal treatment test for corncob with the continuous

2 flow type reactor.

\begin{tabular}{|c|c|c|c|c|c|c|c|c|c|c|c|c|}
\hline \multicolumn{4}{|c|}{ Operation conditions } & \multicolumn{4}{|c|}{ Raw material } & \multicolumn{5}{|c|}{ Reaction Products } \\
\hline \multirow{3}{*}{$\begin{array}{l}\text { Temper } \\
\text { (setting) }\end{array}$} & \multirow{3}{*}{$\begin{array}{r}\text { ature }\left[{ }^{\circ} \mathrm{C}\right] \\
(\text { actual })^{\mathrm{a}}\end{array}$} & \multirow{3}{*}{$\begin{array}{l}\text { Time } \\
{[\mathrm{min}]^{\mathrm{b}}}\end{array}$} & \multirow{3}{*}{$\begin{array}{l}\text { Flow rate } \\
{[\mathrm{g} / \mathrm{min}]}\end{array}$} & \multirow{2}{*}{\multicolumn{2}{|c|}{$\frac{\text { Corncob }}{\text { Contents [wt } \%]}$}} & \multicolumn{2}{|l|}{ Water } & \multicolumn{2}{|l|}{ Residual fraction } & \multicolumn{3}{|l|}{ Soluble fraction } \\
\hline & & & & & & Contents & $w t \%]$ & \multirow[t]{2}{*}{ Contents[wt\%] } & \multirow[t]{2}{*}{ Solubilization[\%] ${ }^{c}$} & \multirow[t]{2}{*}{ Contents[wt\%] } & \multirow[t]{2}{*}{$\mathrm{pH}[-]$} & \multirow[t]{2}{*}{ Brix [\%] } \\
\hline & & & & (setting) & (actual) & (setting) & (actual) & & & & & \\
\hline \multirow{5}{*}{200} & 198 & 9.5 & 330 & \multirow{5}{*}{13.5} & - & \multirow{5}{*}{86.5} & - & - & - & - & 3.4 & 7.2 \\
\hline & 202 & 9.3 & 333 & & 13.6 & & & 9.2 & 32.8 & 90.8 & 3.5 & 7.2 \\
\hline & 202 & 9.2 & 337 & & 13.6 & & & 9.0 & 33.7 & 91.0 & 3.5 & 7.3 \\
\hline & 201 & 10.7 & 291 & & 12.7 & & & 8.3 & 34.9 & 91.7 & 3.5 & 7.0 \\
\hline & 203 & 12.1 & 256 & & - & & - & - & - & - & 3.4 & 7.2 \\
\hline \multirow{3}{*}{205} & 206 & 8.6 & 360 & \multirow{3}{*}{13.5} & - & \multirow{3}{*}{86.5} & - & - & - & - & 3.5 & 7.0 \\
\hline & 207 & 9.3 & 333 & & 13.1 & & & 8.8 & 33.2 & 91.2 & 3.5 & 7.2 \\
\hline & 207 & 10.3 & 300 & & - & & - & - & - & - & 3.4 & 7.3 \\
\hline 210 & 210 & 8.9 & 345 & 13.5 & - & 86.5 & - & - & - & - & 3.4 & 7.0 \\
\hline
\end{tabular}

$3{ }^{a}$ Actual reaction temperature (averaged temperatures of each reaction divisions R1 to R4, during sampling period).

$4 \quad{ }^{b}$ Residence time in the reactor tube [min]

$5=$ Volume of reactor tube $\left[\mathrm{cm}^{3}\right] /$ Mass flow rate of slurry raw material $[\mathrm{g} / \mathrm{min}] \times$ Density at elevated temperature $\left[\mathrm{g} / \mathrm{cm}^{3}\right]$.

$6 \quad \mathrm{c}$ Solubilization ratio of raw material [\%]

$7=\{1-($ Weight of residual fraction $[\mathrm{g}] /$ Weight of dry corncob in fed raw material $[\mathrm{g}])\} \times 100$.

8 "-" means experimental data lacked. 
1 Table 3. Solubilized hemicellulose fraction of corncob by the hydrothermal treatment with the

2 continuous flow type reactor at various reaction conditions.

\begin{tabular}{cccccccccc}
\hline \multirow{2}{*}{$\begin{array}{c}\text { Temperature } \\
{\left[{ }^{\circ} \mathrm{C}\right]}\end{array}$} & $\begin{array}{c}\text { Time } \\
{[\mathrm{min}]}\end{array}$ & \multicolumn{7}{c}{ Concentration of sugar products in the soluble fraction [wt\%] } \\
\cline { 3 - 9 } & 9.5 & 3.68 & 0.96 & 2.72 & 0.78 & 0.30 & 0.26 & 0.17 \\
& 9.3 & 3.55 & 1.19 & 2.36 & 0.73 & 0.27 & 0.25 & 0.16 \\
200 & 9.2 & 3.70 & 1.07 & 2.63 & 0.74 & 0.29 & 0.25 & 0.15 \\
& 10.7 & 3.37 & 0.81 & 2.56 & 0.83 & 0.31 & 0.25 & 0.17 \\
& 12.1 & 3.18 & 0.56 & 2.62 & 1.07 & 0.33 & 0.26 & 0.23 \\
\hline \multirow{2}{*}{205} & 8.6 & 3.75 & 1.51 & 2.24 & 0.53 & 0.25 & 0.23 & 0.08 \\
& 9.3 & 3.45 & 0.70 & 2.75 & 0.79 & 0.27 & 0.24 & 0.19 \\
& 10.3 & 3.49 & 0.71 & 2.78 & 0.93 & 0.29 & 0.26 & 0.21 \\
\hline
\end{tabular}

$3 *$ Residence time in the reactor tube defined in Table 2.

4 XO: Xylose-oligomer (total of $\mathrm{XO}_{\mathrm{H}}$ and $\mathrm{XO}_{\mathrm{L}}$ ).

$5 \quad \mathrm{XO}_{\mathrm{H}}$ : Higher-xylooligosaccharide $(\geq \mathrm{DP} 11)$.

$6 \mathrm{XO}_{\mathrm{L}}$ : Xylooligosaccharide (DP2 to DP10). 
1 Table 4. Yields of solubilized hemicellulose fraction and residual fraction for hydrothermal

2 treatment of corncob with the continuous flow type reactor at various reaction conditions.

\begin{tabular}{|c|c|c|c|c|c|c|c|c|c|c|c|}
\hline \multirow{2}{*}{$\begin{array}{c}\text { Temp. } \\
{\left[{ }^{\circ} \mathrm{C}\right]}\end{array}$} & \multirow{2}{*}{$\underset{[\mathrm{min}]}{\text { Time }}$} & \multicolumn{10}{|c|}{ Yield of products $[\mathrm{wt} \%$, as basis for dry corncob] $* *$} \\
\hline & & $\begin{array}{l}\text { Soluble } \\
\text { fraction }\end{array}$ & $\mathrm{XO}$ & $\mathrm{XO}_{\mathrm{H}}$ & $\mathrm{XO}_{\mathrm{L}}$ & Xyl & Glu & Ara & Furfural & $\begin{array}{l}\text { Residual } \\
\text { fraction }\end{array}$ & Total \\
\hline \multirow{3}{*}{200} & 9.3 & 32.8 & 23.7 & 6.2 & 17.5 & 4.9 & 1.8 & 1.7 & 1.0 & 67.2 & 100.3 \\
\hline & 9.2 & 33.7 & 24.8 & 8.3 & 16.5 & 5.0 & 1.9 & 1.7 & 1.0 & 66.3 & 100.6 \\
\hline & 10.7 & 34.9 & 24.4 & 7.1 & 17.3 & 6.0 & 2.2 & 1.8 & 1.3 & 65.1 & 100.8 \\
\hline 205 & 9.3 & 33.2 & 24.0 & 4.8 & 19.2 & 5.5 & 1.9 & 1.7 & 1.3 & 66.8 & 101.2 \\
\hline
\end{tabular}

$3 *$ Residence time in the reactor tube defined in Table 2.

$4 \quad * *$ Yield of product $[\mathrm{wt} \%]=$ Weight of each product in the soluble fraction $[\mathrm{g}] /$ Weight of corncob in fed raw material $[\mathrm{g}] \times 100$.

5 XO: Xylose-oligomer (total of $\mathrm{XO}_{\mathrm{H}}$ and $\mathrm{XO}_{\mathrm{L}}$ ).

$6 \quad \mathrm{XO}_{\mathrm{H}}$ : Higher-xylooligosaccharide $(\geq \mathrm{DP} 11)$.

$7 \quad \mathrm{XO}_{\mathrm{L}}$ : Xylooligosaccharide (DP2 to DP10). 
1 Table 5. Theoretical yields of xylan related products (xylooligosaccharide, xylose, furfural, etc.) on

2 the hydrothermal treatment of corncob.

\begin{tabular}{|c|c|c|c|c|c|c|}
\hline \multirow{2}{*}{$\begin{array}{c}\text { Temp. } \\
{\left[{ }^{\circ} \mathrm{C}\right]}\end{array}$} & \multirow{2}{*}{$\begin{array}{c}\text { Time * } \\
{[\mathrm{min}]}\end{array}$} & \multicolumn{5}{|c|}{ Theoretical yield of xylan related products $[\mathrm{wt} \%$, as basis for xylan in corncob] $* *$} \\
\hline & & $\begin{array}{l}\text { Soluble fraction } \\
\quad \text { (as Xylose-oligomer) }\end{array}$ & (as Xylose) & (as Furfural) & $\begin{array}{l}\text { Residual fraction } \\
\text { (as Xylan) }\end{array}$ & Total \\
\hline 200 & 10.7 & 62.2 & 20.0 & 6.6 & 7.5 & 96.3 \\
\hline 205 & 9.3 & 59.9 & 18.5 & 6.8 & 8.0 & 93.2 \\
\hline
\end{tabular}

$3 *$ Residence time in the reactor tube defined in Table 2.

$4 \quad * *$ Theoretical yield $[\mathrm{wt} \%]=$ Weight of xylose unit in each product $[\mathrm{g}] /$ Weight of xylose unit in fed raw material $[\mathrm{g}] \times 100$.

5 
Fig.1. Makishima et al.

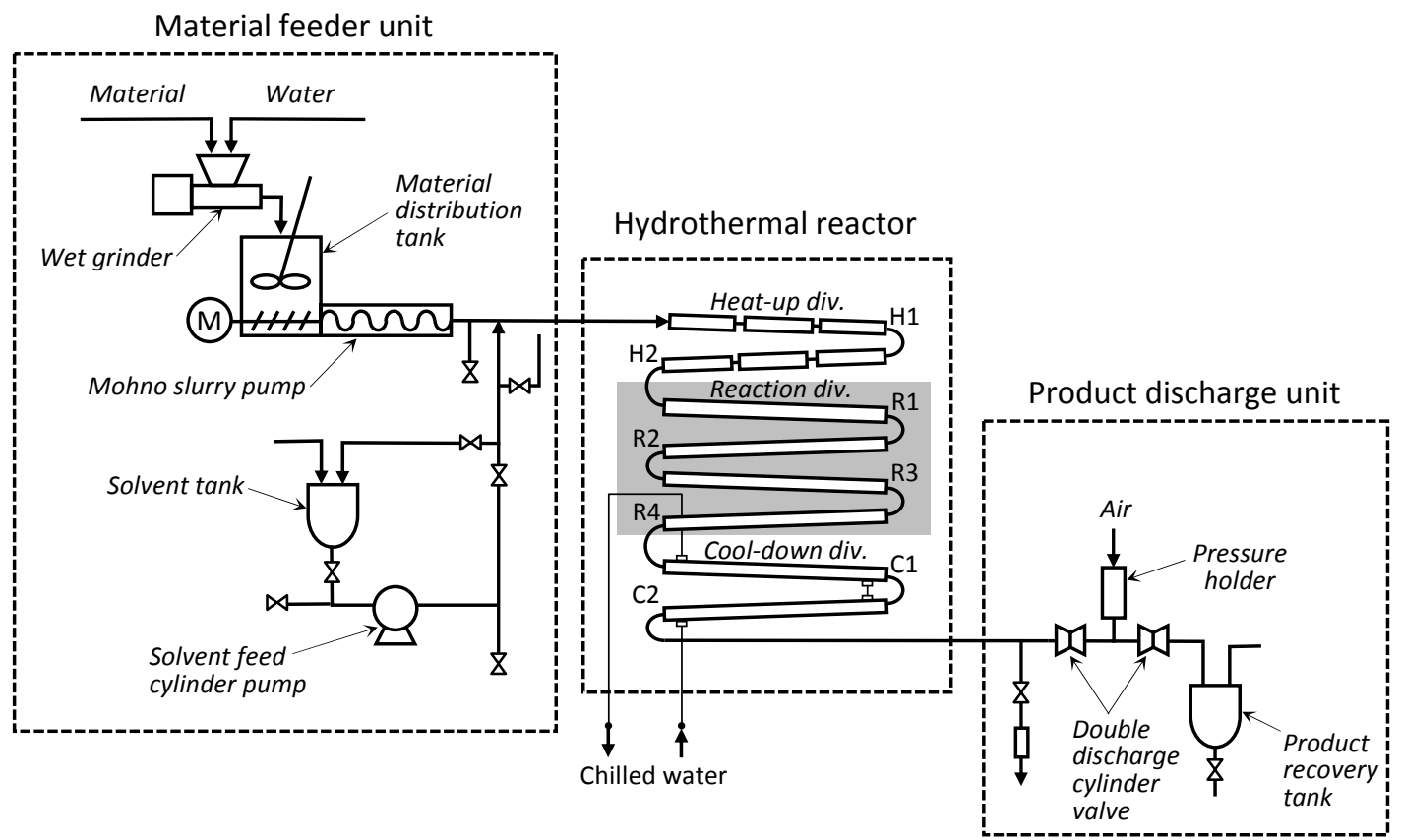


Fig. 2. Makishima et al.
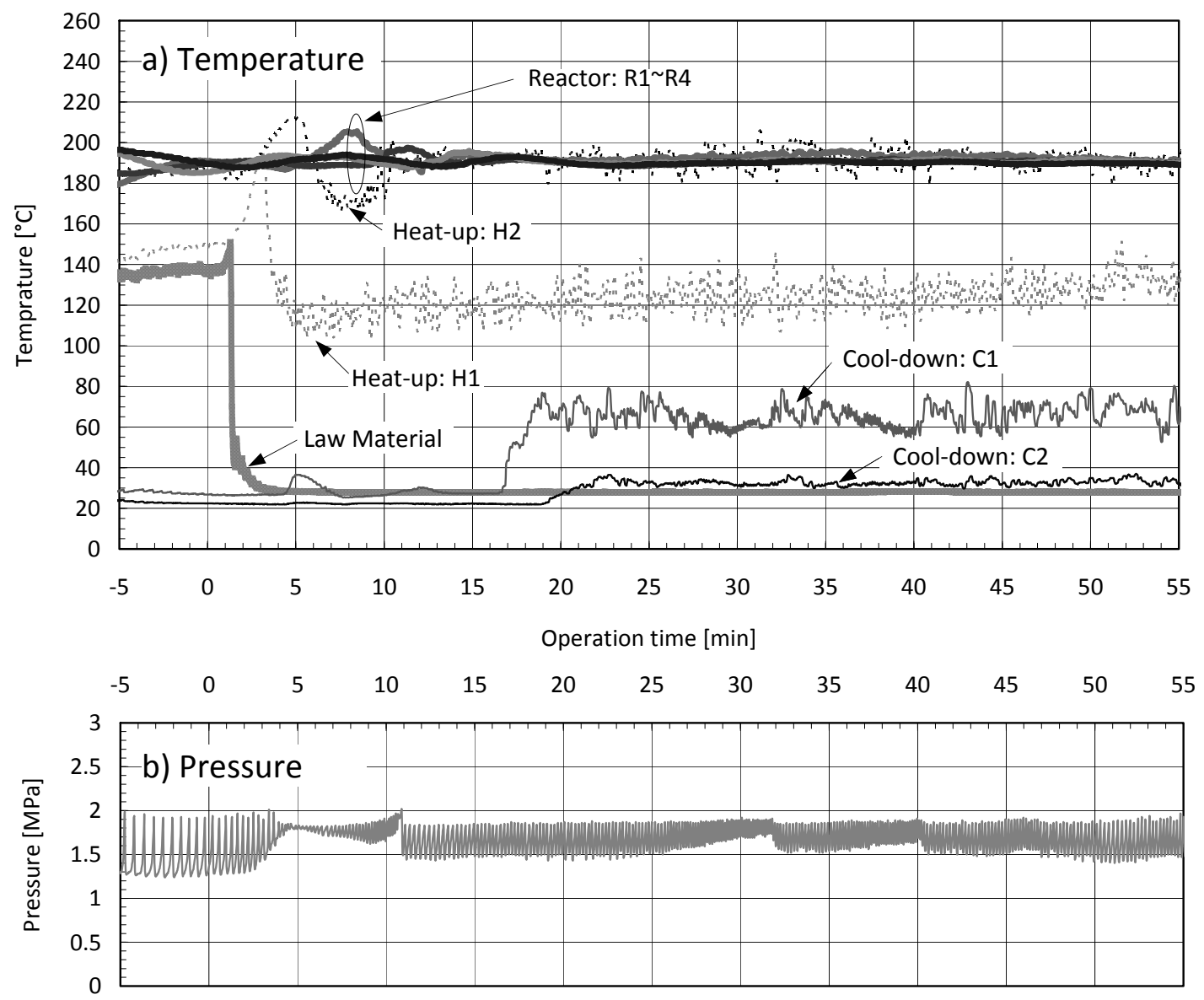
Fig. 3. Makishima et al.

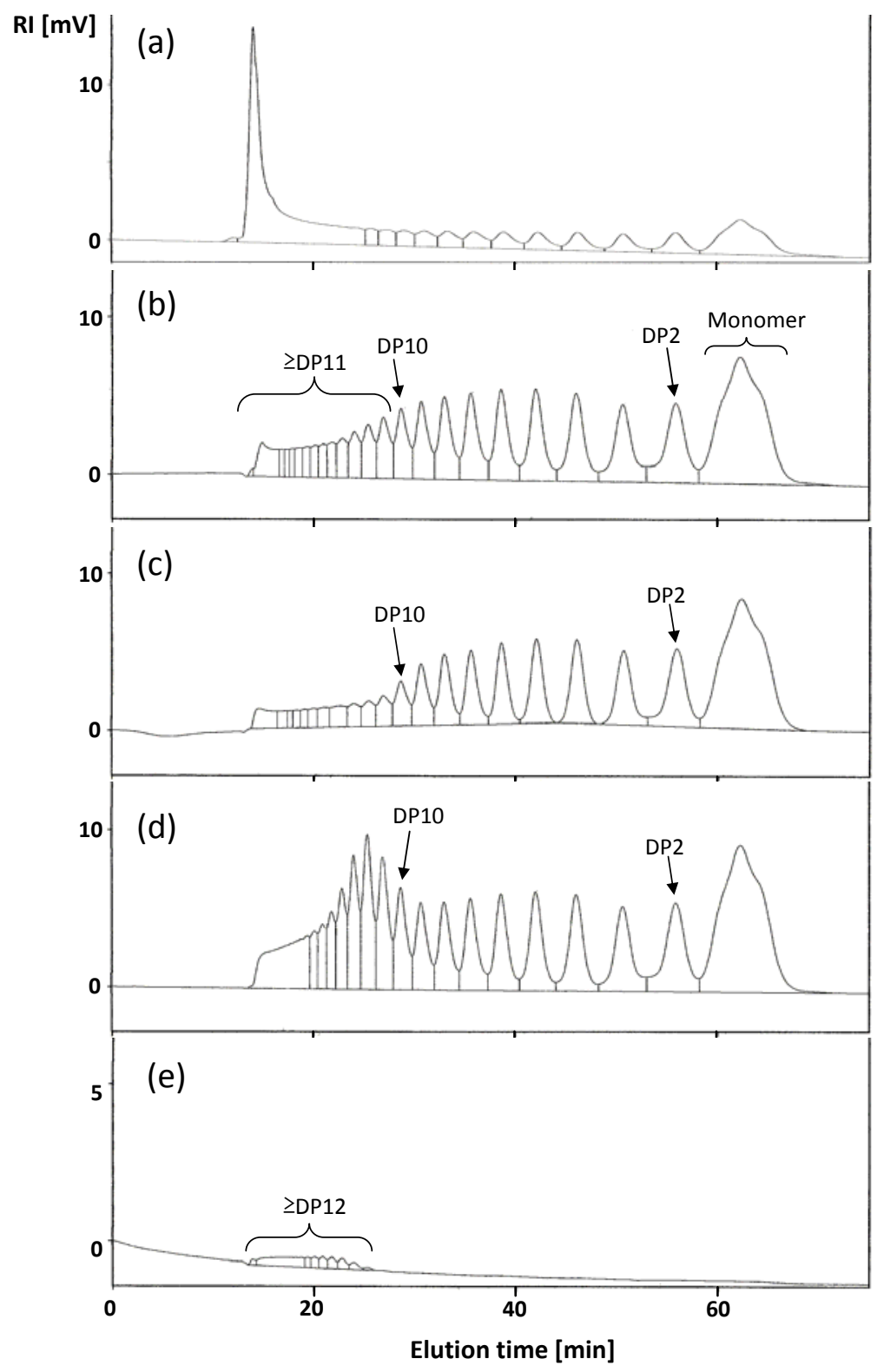

